\title{
Studi Komparasi Perancangan Balok Struktural Berdasarkan SNI 2847-2002, SNI 2847-2013 Dan SNI 2847-2019
}

\author{
Noerman Adi Prasetya ${ }^{* 1}$, Ahmad Hernadi ${ }^{2}$, Agung Nugroho ${ }^{3}$ \\ ${ }^{1,2}$ Universitas Borneo Tarakan, Jalan Amal Lama No. 01 Tarakan, Indonesia \\ ${ }^{3}$ Program Studi Teknik Sipil, FT UBT, Tarakan \\ Email:*1noermanp@gmail.com
}

Received 18 March 2021; Reviewed 08 August 2021; Accepted 04 November 2021

Journal Homepage: http://jurnal.borneo.ac.id/index.php/borneoengineering

\begin{abstract}
This study aims to determine the difference in structural beam design using SNI 2847-2002, SNI 2847-2013 and SNI 2847-2019 by comparing the bending and shear reinforcement in the case study of the Faculty of Health Sciences Building, University of Borneo Tarakan. The results of the comparisons include: the maximum reinforcement ratio at SNI 2847-2013 and 2019 is around 16,667\% smaller than SNI 2847-2002, the flexural capacity of the beam design results from SNI 2847-2013 and 2019 increases by about 12.5\% compared to SNI 2847-2002, The shear capacity of concrete (Vc) designed with SNI 2847-2013 and 2019 increased by about 2\% compared to SNI 2847-2002, as well as the design shear capacity of the accumulated concrete and shear reinforcement designed by SNI 2847-2013 and 2019 increased no more than 1\% compared to SNI 2847-2002.
\end{abstract}

Keywords: Flexure Reinforced, Shear Reinforced, Strength Reduction Factor, Standard Update

\begin{abstract}
Abstrak
Penelitian ini bertujuan untuk mengetahui selisih desain balok struktural menggunakan SNI 28472002, SNI 2847-2013 dan SNI 2847-2019 dengan cara melakukan komparasi tulangan lentur dan tulangan geser pada studi kasus Gedung Fakultas Ilmu Kesehatan Universitas Borneo Tarakan. Hasil komparasi antara lain: rasio tulangan maksimum pada SNI 2847-2013 dan 2019 lebih kecil sekitar 16.667\% dibandingkan SNI 2847-2002, kapasitas lentur rencana balok hasil desain dengan SNI 2847-2013 dan 2019 meningkat sekitar 12.5\% dibandingkan dengan SNI 2847-2002, kapasitas geser dari beton (Vc) hasil desain dengan SNI 2847-2013 dan 2019 meningkat sekitar 2\% dibandingkan dengan SNI 2847-2002, serta kapasitas geser rencana dari akumulasi beton dan tulangan geser hasil desain dengan SNI 2847-2013 dan 2019 meningkat tidak lebih dari 1\% dibandingkan dengan SNI 2847-2002.
\end{abstract}

Kata kunci: Tulangan Lentur, Tulangan Geser, Faktor Reduksi Kekuatan, Pembaharuan Standar

\section{Pendahuluan}

Kebutuhan pasar, perkembangan ilmu pengetahuan dan teknologi, pemeliharan dan penilaian kelayakan struktur bangunan, khususnya bangunan beton bertulang menjadi dasar Badan Standarisasi Nasional (SNI) untuk melakukan pembaharuan beberapa SNI strategis salah satunya adalah SNI 2847:2019 mengenai "Persyaratan Beton Struktural Untuk Bangunan Gedung dan Penjelasan". Standar ini telah dipersiapkan oleh Komite Teknis Bahan Konstruksi Bangunan dan Rekayasa Sipil (91-01) melalui Gugus Kerja Bahan Bangunan pada Subkomite Teknis Bahan, 
Sains, Struktur dan Konstruksi Bangunan (91-01-S4) dan telah melalui tahap jajak pendapat pada tanggal 30 Agustus 2019 sampai dengan 29 Oktober 2019, dengan hasil akhir disetujui menjadi SNI. Peraturan yang baru ini sekaligus menggantikan peraturan sebelumnya, yaitu 03-SNI 2847 2002 yang sudah berlaku lebih dari 17 tahun dan SNI 2847 - 2013 yang sudah berlaku kurang lebih 6 tahun. Seperti halnya peraturan terdahulu yang menganut tata cara dari American Concrete Institute (ACI), maka SNI 2847:2019 disusun dengan mengacu pada ACI318M-14 dan ACI318RM-14.

Perubahan yang cukup signifikan pada beberapa detail isi pedoman yang diatur dalam SNI 2847:2019 harus dipahami dengan baik oleh pelaku konstruksi, terutama para perencana struktur. Perubahan besar terlihat pada organisasi pasal yang menjadi lebih ringkas dengan pengelompokkan-pengelompokkan item perhitungan berdasarkan elemen strukturnya, disamping itu juga terdapat perubahan teknis yang signifikan pada beberapa elemen struktural, diantaranya persyaratan sistem struktur, struktur tahan gempa, dan persyaratan desain yang semakin fleksibel seiring meningkatnya teknologi terkini.

Penentuan kriteria penampang tersebut didasarkan pada regangan tarik netto (ct), yang terjadi pada tulangan baja terluar. Rasio tulangan maksimum ditentukan berdasarkan regangan tarik minimum yang boleh terjadi, sesuai dengan yang ditentukan dalam peraturan. Hal ini sedikit berbeda dari peraturan sebelumnya, SNI 2847-2002, yang menyatakan bahwa rasio tulangan maksimum dibatasi sebesar 0,75 dari rasio tulangan dalam kondisi seimbang. Selain itu, perubahan juga terjadi pada faktor reduksi kekuatan, $\varphi$. Jika pada SNI 2002, nilai $\varphi$ ditentukan seragam sebesar 0,8 , maka pada SNI 2847-2013 nilai $\varphi$ diperbolehkan diambil sebesar 0,90 jika $\varepsilon$ t mencapai 0,005 atau lebih dan direduksi secara linear hingga $\varepsilon_{\mathrm{t}}$ mencapai batas minimum yang diizinkan sebesar 0,004 (Setiawan, 2015), hal yang serupa juga yang tercantum pada SNI 2847-2013.

Perkembangan teknologi yang cepat pada periode 2002, 2013 sampai dengan 2019 menyebabkan desain balok struktural pada SNI 2847-2019 menjadi lebih fleksibel dan efisien. Berdasarkan hal tersebut, gambaran secara rinci mengenai selisih desain balok struktural menggunakan SNI 28472002, SNI 2847-2013 dan SNI 2847-2019 dapat terlihat dengan komparasi tulangan lentur dan tulangan geser pada studi kasus Gedung Fakultas Ilmu Kesehatan Universitas Borneo Tarakan yang dalam perencanaannya menggunakan SNI 2847:2002.

\section{Metode Penelitian}

\subsection{Lokasi Penelitian}

Penelitian dilakukan di Laboratorium Teknik Sipil Universitas Borneo Tarakan dengan objek penelitian adalah Gedung Fakultas Ilmu Kesehatan Universitas Borneo Tarakan.

\subsection{Survei lapangan}

Survei lapangan meliputi pengamatan secara visual (Visual Check), baik dengan mata telanjang maupun dengan bantuan kamera dan pemeriksaaan kerusakaannya, khususnya retak-retak. Investigasi cacat struktur yang lain seperti keropos, berlobang, mengelupas dan sebagainya. Kegiatan ini dilakukan terutama terhadap komponen yang berfungsi memikul beban-beban, baik beban vertical maupun beban horizontal. Hasil dari kegiatan ini telah berupa penggambaran polapola keretakan pada elemen balok struktur "Crack Pattern".

\subsection{Pengumpulan Data}

Pengumpulan data pada penelitian ini meliputi data primer dan data sekunder. Data primer yang digunakan merupakan data yang diambil di lapangan secara langsung berupa pengujian mutu bahan dengan cara non destructive test dengan Hammer Test berdasarkan SNI 03-4430-1997 dan Ultrasonic Pulse Velocitymeter (UPV) berdasarkan standar pengujian ASTM C597, sedangkan data 
sekunder yang digunakan merupakan hasil pemeriksaan gambar-gambar yang ada, data uji mutu beton, dan data spesifikasi teknik gedung.

\subsection{Analisis Struktur}

Analisis struktur dalam rangka evaluasi kelaikan struktur yang didasarkan pada ukuran dan kondisi eksisting yang ada dengan tujuan untuk mendapatkan gaya-gaya dalam akibat berbagai kombinasi pembebanan, kemudian dari data primer yang diperoleh sebelumnya dilakukan pemodelan struktur pada Gambar 1 untuk dianalisis sehingga dihasilkan gaya-gaya lentur dan geser elemen balok yang selanjutnya digunakan untuk desain tulangan.

Pada tahap kegiatan ini dilakukan analisis terhadap perencanaan (mengacu pada gambar-gambar bestek perencanaan) dan analisis terhadap pelaksanaan (dikarenakan tidak ditemukan adanya dokumen "as built drawing", maka digunakan data condition drawing dan hasil data pengujian lapangan maupun laboratorium yang didapatkan pada tahapan kegiatan sebelumnya.

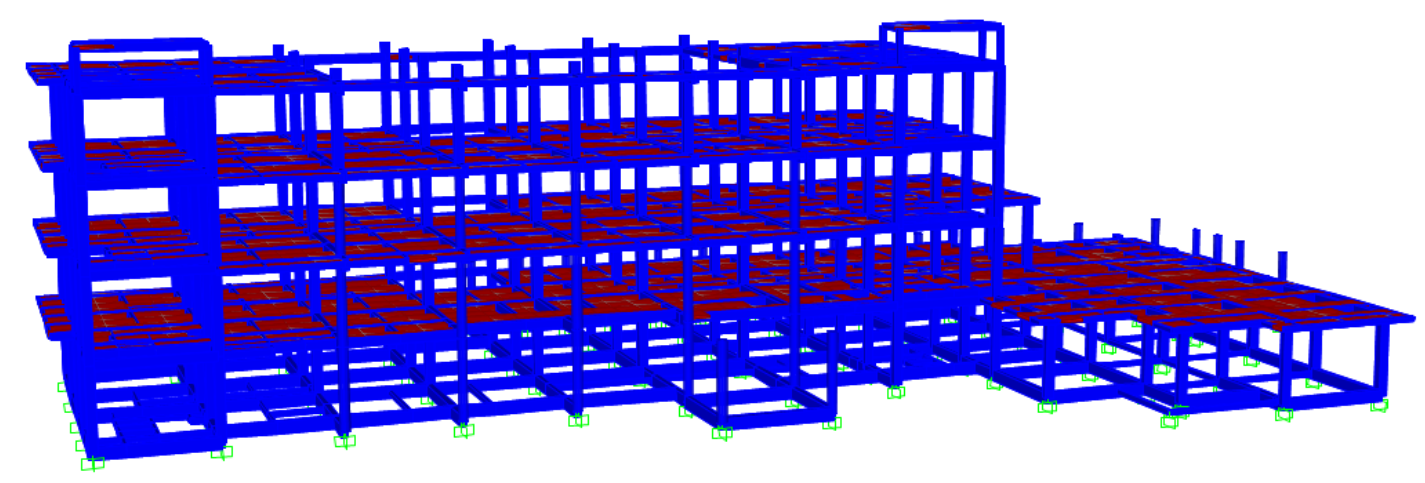

Gambar 1 Pemodelan Struktur Gedung FIKES - UBT

\subsection{Evaluasi Hasil Analisis Struktur}

Dari hasil analisis struktur ini akan dilakukan evaluasi berupa kontrol kapasitas, khususnya elemen balok struktural sebagai pemikul beban-beban yang bekerja. Nilai kekuatan kondisi eksisting struktur akan disimulasikan untuk kondisi layan struktur nantinya menggunakan SNI-2847-2002, SNI 2847-2013 dan SNI 2847-2019.

\subsection{Desain Tulangan}

Dari hasil evaluasi hasil analisa struktur sebelumnya diperoleh gap antara kekuatan menggunakan SNI-2847-2002, SNI 2847-2013 dan SNI 2847-2019, lalu pada tahap ini akan dilakukan pengecekan tulangan Kapasitas lentur dan geser, selanjutnya hasil perhitungan akan disajikan ke dalam grafik untuk dikomparasikan yang selanjutnya dibahas berdasarkan hasil amatan selisih desain tulangan antar pedoman SNI-2847 yang digunakan.

\subsubsection{Desain tulangan lentur}

Tulangan longitudinal tarik maupun tekan pada balok dipasang dengan arah sejajar sumbu balok. Biasanya tulangan tarik dipasang lebih banyak daripada tulangan tekan, kecuali pada balok yang menahan momen lentur kecil (Asroni, 2010). 

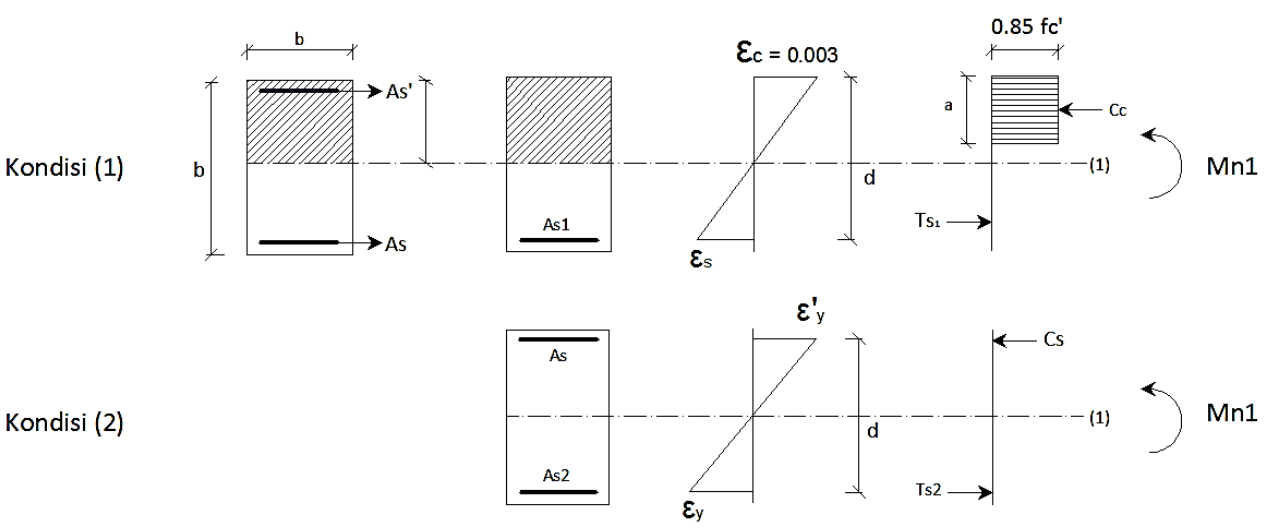

Gambar 3. diagram tegangan-regangan tulangan rangkap (Nawy, 1990) Pada kondisi 1

$$
\begin{aligned}
& T_{s}=T_{c} \\
& A_{S 1}<0,75 A_{S b} \\
& A_{S 1} \cdot f_{y}=0,85 \cdot f_{c}^{\prime} \cdot a \cdot b_{w} \\
& a=\frac{A_{S 1} \cdot f_{y}}{0.85 \cdot f^{\prime} \cdot b_{w}} \\
& M_{n 1}=T_{S} \cdot\left(d-\frac{a}{2}\right) \\
& M_{n 1}=A_{S 1} \cdot f_{y} \cdot\left(d-\frac{1}{2} \cdot \frac{A_{S 1} \cdot f_{y}}{0.85 \cdot f^{\prime} \cdot b_{w}}\right)
\end{aligned}
$$

dimana :

$\mathrm{T}_{\mathrm{s}}=$ Kuat Kuat momen torsi nominal yang disumbangkan oleh beton $(\mathrm{Nm})$

$\mathrm{C}_{\mathrm{c}}=$ Jarak dari serat tekan terluar ke garis netral $(\mathrm{mm})$

$A_{s 1}=$ Luas tulangan $\left(\mathrm{mm}^{2}\right)$

$\mathrm{A}_{\mathrm{sb}}=$ Luas tulangan $\left(\mathrm{mm}^{2}\right)$

$f_{y}=$ Mutu baja (Mpa)

$f_{c}^{\prime}=$ Kuat tekan beton (Mpa)

$\mathrm{b}_{\mathrm{w}}=$ Lebar badan $(\mathrm{mm})$

$\mathrm{M}_{\mathrm{n} 1}=$ Momen nominal $(\mathrm{kNm})$

$\mathrm{d}=$ Jarak antar titik berat tulangan tarik ke serat tekan terluar $(\mathrm{mm})$

$\mathrm{d}^{\prime}=$ Jarak pusat tulangan lentur ke sisi beton (mm)

Selisih momen :

$$
\begin{aligned}
& M_{n 2}=T_{S 2} \cdot\left(d-d^{\prime}\right) \\
& M_{n 2}=\frac{M_{u}}{\phi} \cdot M_{n 1} \\
& f_{s 2}=f_{y} \\
& M_{n 2}=A_{S 2} \cdot f_{S 2} \cdot\left(d-d^{\prime}\right) \\
& A_{s}{ }^{\prime}=A_{S 2}=\left(\frac{M_{n 2}}{f_{S 2}\left(d-d^{\prime}\right.}\right)
\end{aligned}
$$


Sehingga diperoleh :

Tulangan tarik : $A_{s}=A_{s 1}+A_{s 2}$

Tulangan tekan : $A_{s^{\prime}}$

dimana :

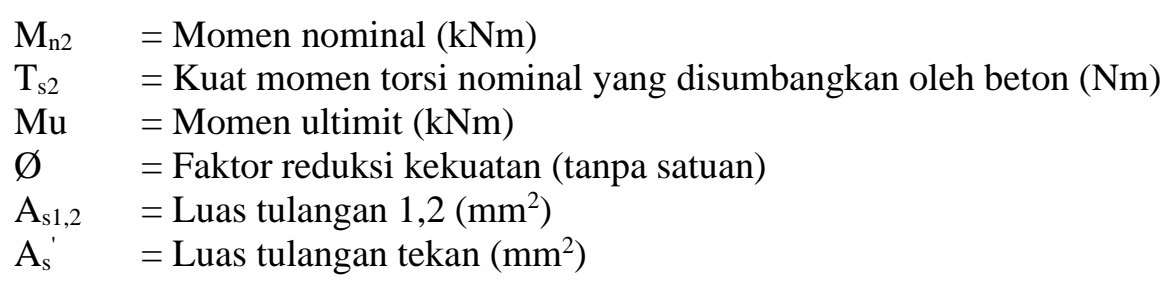

SNI 28472013 dan SNI 28472019 menjelaskan adanya persyaratan mengenai komponen struktur penahan lentur (balok) yaitu sesuai dengan persamaan berikut 2.12 :

$$
A_{S \min }=\frac{\sqrt{f_{c}^{\prime}}}{4 f_{y}} b_{w} \cdot d
$$

Namun, nilai $A_{s \min }$ tidak kurang dari $1,4 b_{w} d / f_{y}$

dimana :

$$
\begin{aligned}
A_{\text {smin }} & =\text { Luas tulangan minimal }(\mathrm{mm} 2) \\
f_{c}{ }^{\prime} & =\text { Kuat tekan beton }(\mathrm{MPa}) \\
f y & =\text { Kuat leleh baja yang disyaratkan }(\mathrm{MPa}) \\
b w & =\text { lebar badan balok }(\mathrm{mm})
\end{aligned}
$$

2.7.2. Desain tulangan geser

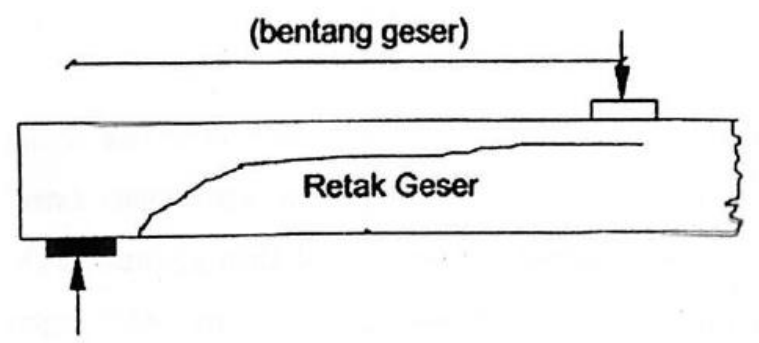

Gambar 4. Tipikal kerusakan geser lentur (Nawy, 1998)

Berdasarkan SNI 28472013 dan SNI 2847 2019, dasar perhitungan tulangan geser balok seperti Persamaan 2.13 berikut:

$$
V_{u} \leq \phi V_{n} ; \phi=0.75
$$

dimana :

$$
\begin{aligned}
V_{n} & =\text { kuat geser nominal }(\mathrm{kN}) \\
V_{n} & =\text { gaya geser terfaktor }(\mathrm{kN}) \\
\varnothing & =\text { faktor reduksi }
\end{aligned}
$$

Sedangkan, 


$$
V_{n}=V_{c}+V_{s}
$$

dimana :

$V_{c}=$ kuat geser nominal yang disumbangkan oleh beton $(\mathrm{kN})$

$V_{s}=$ kuat geser nominal yang disumbangkan oleh tulangan geser $(\mathrm{kN})$

Ketika proses desain yang dihitung yaitu jumlah tulangan geser yang diperlukan sehingga yang dicari adalah VS . BSN (2013) menjelaskan bahwa kuat geser VS tidak boleh melebihi kuat geser maksimum VS maks, yaitu dirumusakan pada Persamaan 2.15 sebagai berikut:

$$
V_{\text {Smaks }}=\frac{2 \sqrt{f_{c}{ }^{\prime}}}{3} b_{w} \cdot d
$$

dimana :

$$
\begin{array}{ll}
b_{w} & =\text { lebar badan }(\mathrm{mm}) \\
V_{s} \text { maks } & =\text { kekuatan geser sengkang }(\mathrm{kN}) \\
d & =\text { jarak dari serat tekan beton terluar ke titik berat tulangan }(\mathrm{mm}) \\
f^{\prime}{ }_{c} & =\text { kuat tekan beton }(\mathrm{MPa})
\end{array}
$$

Secara grafik syarat tulangan geser tersebut dapat dilihat pada Gambar 5 berikut ini.

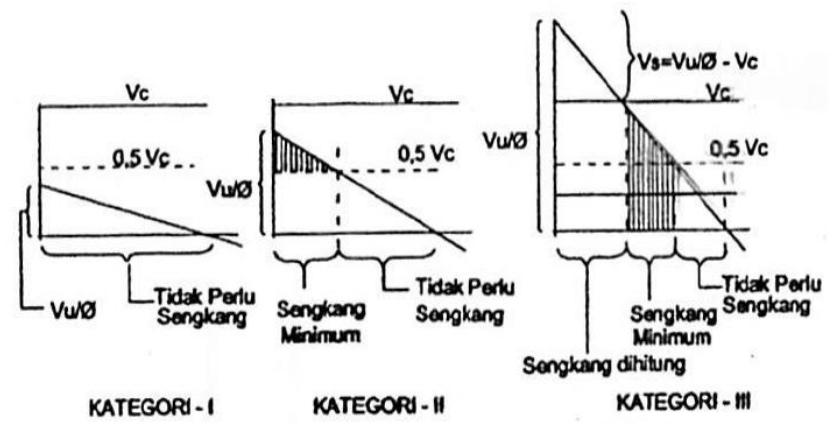

Gambar 5. Diagram Gaya Geser Balok (Priyosulistyo, 2010)

\section{Hasil dan Pembahasan}

Data sekunder yang di peroleh adalah gambar-gambar dan data uji mutu beton, sedangkan data primer yang diambil di lapangan berupa pengujian mutu bahan dengan Hammer Test dan Ultrasonic Pulse Velocitymeter (UPV) yang mana data sekunder dan data primer tersebut menjadi dasar acuan untuk memodelkan gedung FIKES UBT dalam penelitian ini. Adapun besaran parameter mutu beton (fc') berdasarkan pengujian di lapangan yang digunakan dalam penelitian ini adalah sebesar 20.75Mpa dan mutu tulangan baja adalah $400 \mathrm{Mpa}$.

\subsection{Hasil Analisis Gaya Dalam (Internal Forces) Balok Struktur}


Tabel 1 Hasil Analisis Gaya Dalam Balok Struktur

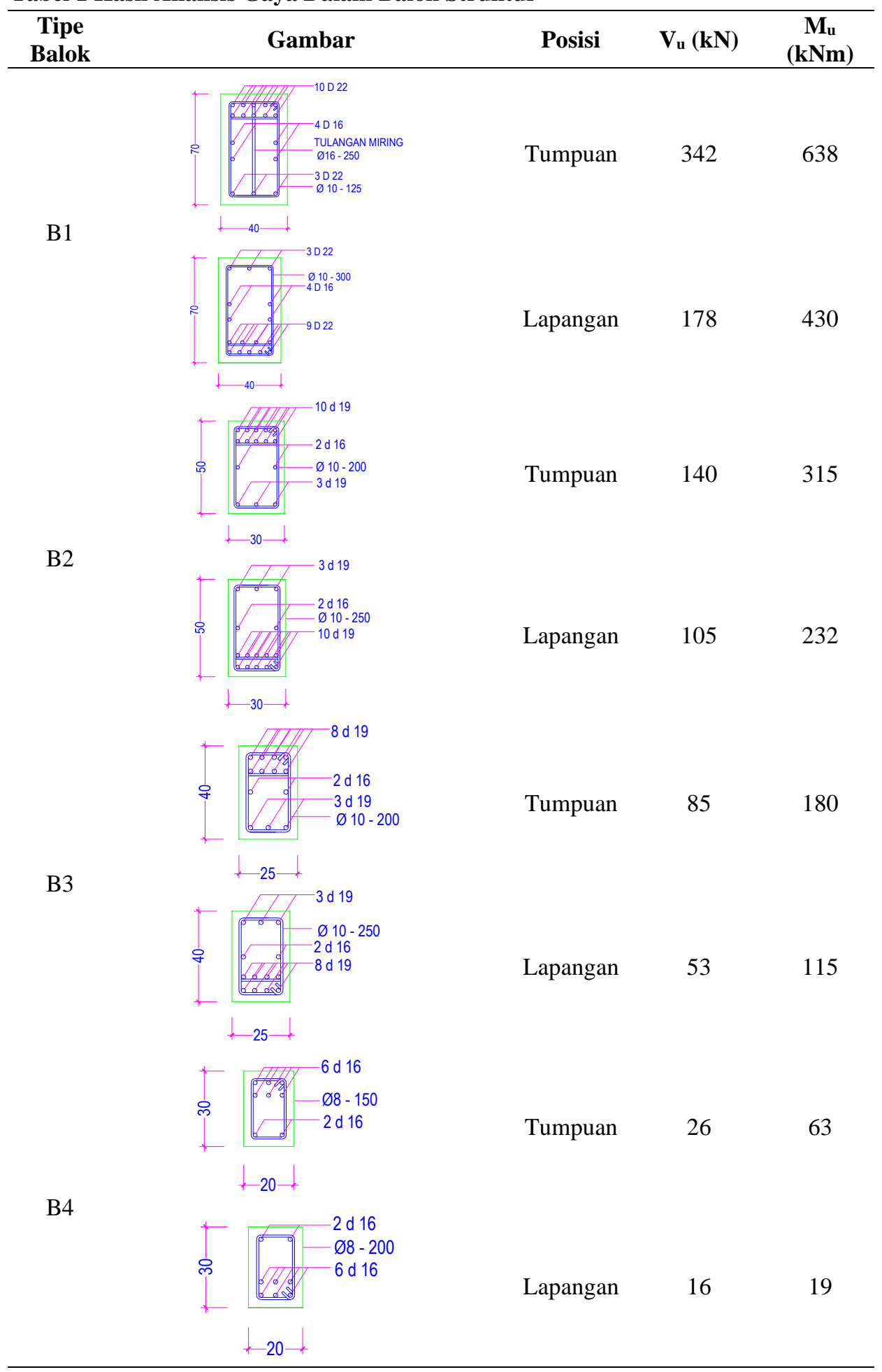

\subsection{Hasil Desain Tulangan Lentur Balok Struktur}

Hasil perhitungan tulangan longitudinal pada penampang dari elemen balok gedung FIKES-UBT disajikan dalam bentuk tabel yang berisikan parameter-parameter perhitungan yang mencakup momen ultimate, diameter dan jumlah tulangan, rasio tulangan, tinggi blok tekan penampang, , nilai batas regangan tarik sampai dengan diperoleh kapasitas lentur penampang dengan desain tulangan menggunakan perhitungan tulangan rangkap yang kemudian dipecah menjadi beberapa segmen perhitungan dalam rangka untuk memudahkan dalam pengklasteran jenis evaluasi. 
Adapun hasil perhitungan tulangan lentur/longitudinal dapat dilihat pada Lampiran Tabel 2, Tabel 3, Tabel 4, dan Tabel 5 dapat diketahui bahwa Rasio tulangan maksimum pada SNI 2847-2013 dan 2019 lebih kecil sekitar 16.667\% dibandingkan SNI 2847-2002 dan kapasitas lentur rencana balok hasil desain dengan SNI 2847-2013 dan 2019 meningkat sekitar 12.5\% dibandingkan dengan SNI 2847-2002.

\subsection{Hasil Desain Geser Balok Struktur}

Hasil perhitungan perkuatan geser pada penampang dari elemen balok gedung FIKES-UBT disajikan dalam bentuk tabel yang berisikan parameter-parameter perhitungan sampai dengan diperoleh kapasitas geser penampang dengan desain tulangan menggunakan perhitungan tulangan rangkap yang kemudian dipecah menjadi beberapa segmen perhitungan dalam rangka untuk memudahkan dalam pengklasteran jenis evaluasi. Adapun hasil perhitungan tulangan longitudinal dapat dilihat dalam Tabel 6, Tabel 7, Tabel 8, dan Tabel 9 pada Lampiran.

Dari Tabel 6, Tabel 7,Tabel 8, dan Tabel 9 pada Lampiran dapat diketahui bahwa kapasitas geser dari beton $(V c)$ hasil desain dengan SNI 2847-2013 dan 2019 meningkat sekitar 2\% dibandingkan dengan SNI 2847-2002 dan untuk kapasitas geser rencana dari akumulasi beton dan tulangan geser hasil desain dengan SNI 2847-2013 dan 2019 meningkat tidak lebih dari 1\% dibandingkan dengan SNI 2847-2002.

\section{Kesimpulan}

Berdasarkan hasil studi komparasi balok struktural untuk beton normal dengan mengambil contoh kasus pada Gedung Fakultas Ilmu Kesehatan Universitas Borneo Tarakan diperoleh beberapa kesimpulan sebagai berikut:

1. Ketentuan-ketentuan perhitungan lentur dan geser untuk balok struktural beton normal pada SNI 2847 -2013 sama dengan SNI 2847-2019

2. Perbedaan ketentuan parameter antara SNI 2847-2002 terhadap dua SNI terbaru lainnya terletak pada penetapan rasio tulangan maksimum $\left(\rho_{\text {maks }}\right)$, faktor reduksi lentur $\left({ }^{\phi}\right)$, serta penetapan kapasitas geser dari beton $\left(V_{c}\right)$

3. Rasio tulangan maksimum pada SNI 2847-2013 dan 2019 lebih kecil sekitar 16.667\% dibandingkan SNI 2847-2002

4. Kapasitas lentur rencana balok hasil desain dengan SNI 2847-2013 dan 2019 meningkat sekitar 12.5\% dibandingkan dengan SNI 2847-2002

5. Kapasitas geser dari beton ( $V c$ ) hasil desain dengan SNI 2847-2013 dan 2019 meningkat sekitar 2\% dibandingkan dengan SNI 2847-2002

6. Kapasitas geser rencana dari akumulasi beton dan tulangan geser hasil desain dengan SNI 2847-2013 dan 2019 meningkat tidak lebih dari 1\% dibandingkan dengan SNI 2847-2002

\section{Ucapan Terima Kasih}

Penulis mengucapkan terima kasih kepada Lembaga Penelitian dan Pengabdian Kepada Masyarakat Universitas Borneo Tarakan yang telah memberikan bantuan dana penelitian sehingga penelitian ini dapat terbiayai dan terlaksana dengan baik.

\section{Daftar Pustaka}

Asroni, A. 2010. Balok dan Pelat Beton Bertulang. Yogyakarta: Graha Ilmu, Hal: 84 
Nawy, E. G, Bambang Suryoatmono, Beton Bertulang Suatu Pendekatan Dasar, Bandung, Eresco, 1990

Nawy, E. G, Bambang Suryoatmono, Beton Bertulang Suatu Pendekatan Dasar, Bandung, Eresco, 1998

Priyosulistyo, H. 2010. Perancangan Analisis Struktur Beton Bertulang I, Yogyakarta: Biro Penerbit Teknik Sipil UGM

Setiawan, A. 2015. Persyaratan Desain Komponen Struktur Lentur Beton Bertulangan Tunggal antara SNI 2847-2002 dan SNI 2847-2013. Jurnal Teknik dan Ilmu Komputer Vol. 04 No.14 Apr-Jun 2015, Universitas Pembangunan Jaya.

SNI 03-2847-2002, Tata Cara Perhitungan Struktur Beton untuk Bangunan Gedung, Perhitungan Struktur Beton untuk Banguan Gedung, Jakarta, 2002.

SNI 03-2847-2013, Tata Cara Perhitungan Struktur Beton untuk Bangunan Gedung, Perhitungan Struktur Beton untuk Banguan Gedung, Jakarta, 2013.

SNI 03-2847-2019, Persyaratan Beton Struktural untuk Bangunan Gedung dan Penjelasan, Jakarta, 2019. 


\section{Lampiran}

Tabel 2 Hasil analisis tulangan lentur balok B1

\begin{tabular}{|c|c|c|c|c|c|c|c|}
\hline & \multirow{2}{*}{ Satuan } & \multicolumn{3}{|c|}{ Tumpuan } & \multicolumn{3}{|c|}{ Lapangan } \\
\hline & & SNI 2002 & SNI 2013 & SNI 2019 & SNI 2002 & SNI 2013 & SNI 2019 \\
\hline $\mathrm{M}_{\mathrm{u}}$ & $\mathrm{kNm}$ & 638 & 638 & 638 & 430 & 430 & 430 \\
\hline$\dot{\emptyset}_{\text {tulangan }}$ & $\mathrm{mm}$ & 22 & 22 & 22 & 22 & 22 & 22 \\
\hline $\mathrm{n}$ tul. tarik & buah & 10 & 10 & 10 & 9 & 9 & 9 \\
\hline $\mathrm{n}$ tul. tekan & buah & 3 & 3 & 3 & 3 & 3 & 3 \\
\hline $\mathrm{A}_{\mathrm{s}}$ & $\mathrm{mm}^{2}$ & 3801 & 3801 & 3801 & 3421 & 3421 & 3421 \\
\hline$A_{s}{ }^{\prime}$ & $\mathrm{mm}^{2}$ & 1140 & 1140 & 1140 & 1140 & 1140 & 1140 \\
\hline$\rho$ & & 0.0156 & 0.0156 & 0.0156 & 0.0140 & 0.0140 & 0.0140 \\
\hline$\rho^{\prime}$ & & 0.0047 & 0.0047 & 0.0047 & 0.0047 & 0.0047 & 0.0047 \\
\hline$\rho-\rho^{\prime}$ & & 0.0109 & 0.0109 & 0.0109 & 0.0093 & 0.0093 & 0.0093 \\
\hline & & tul tekan & tul tekan & tul tekan & tul tekan & tul tekan & tul tekan \\
\hline$\left(\rho-\rho^{\prime}\right) \geq K$ & & belum & belum & belum & belum & belum & belum \\
\hline & & leleh & leleh & leleh & leleh & leleh & leleh \\
\hline$\rho b$ & & 0.0225 & 0.0225 & 0.0225 & 0.0225 & 0.0225 & 0.0225 \\
\hline$\rho_{\text {maks }}$ & & 0.0169 & 0.0141 & 0.0141 & 0.0169 & 0.0141 & 0.0141 \\
\hline & & ok & ok & ok & ok & ok & ok \\
\hline$\left(\rho-\rho^{\prime}\right) \leq \rho m a k s$ & & $\begin{array}{l}\text { terkendali } \\
\text { tarik }\end{array}$ & $\begin{array}{l}\text { terkendali } \\
\text { tarik }\end{array}$ & $\begin{array}{l}\text { terkendali } \\
\text { tarik }\end{array}$ & $\begin{array}{l}\text { terkendali } \\
\text { tarik }\end{array}$ & $\begin{array}{l}\text { terkendali } \\
\text { tarik }\end{array}$ & $\begin{array}{l}\text { terkendali } \\
\text { tarik }\end{array}$ \\
\hline$\rho_{\min }$ & & 0.0035 & 0.0035 & 0.0035 & 0.0035 & 0.0035 & 0.0035 \\
\hline Syarat & & & & & & & \\
\hline$\rho_{\min }<\left(\rho-\rho^{\prime}\right)$ & & memenuhi & memenuhi & memenuhi & memenuhi & memenuhi & memenuhi \\
\hline$<\rho_{\text {maks }}$ & & & & & & & \\
\hline$\beta_{1}$ & & 0.85 & 0.85 & 0.85 & 0.85 & 0.85 & 0.85 \\
\hline $\mathrm{a}$ & $\mathrm{mm}$ & 150.872 & 150.872 & 150.872 & 129.327 & 129.327 & 129.327 \\
\hline $\mathrm{c}$ & $\mathrm{mm}$ & 177.496 & 177.496 & 177.496 & 152.149 & 152.149 & 152.149 \\
\hline$\varepsilon_{\mathrm{t}}$ & & 0.0073 & 0.0073 & 0.0073 & 0.0090 & 0.0090 & 0.0090 \\
\hline$\varepsilon_{\mathrm{t}}>0.005$ & & tarik & tarik & tarik & tarik & tarik & tarik \\
\hline $\mathrm{M}_{\mathrm{n}}$ & $\mathrm{kNm}$ & 806.11 & 806.11 & 806.11 & 734.69 & 734.69 & 734.69 \\
\hline $\mathrm{M}_{\mathrm{r}}$ & $\mathrm{kNm}$ & 644.89 & 725.50 & 725.50 & 587.75 & 661.22 & 661.22 \\
\hline Syarat $M_{r}>M_{u}$ & & memenuhi & memenuhi & memenuhi & memenuhi & memenuhi & memenuhi \\
\hline
\end{tabular}

Tabel 3 Hasil analisis tulangan lentur balok B2

\begin{tabular}{|c|c|c|c|c|c|c|c|}
\hline & \multirow{2}{*}{ Satuan } & \multicolumn{3}{|c|}{ Tumpuan } & \multicolumn{3}{|c|}{ Lapangan } \\
\hline & & SNI 2002 & SNI 2013 & SNI 2019 & SNI 2002 & SNI 2013 & SNI 2019 \\
\hline $\mathrm{M}_{\mathrm{u}}$ & $\mathrm{kNm}$ & 315 & 315 & 315 & 232 & 232 & 232 \\
\hline$\dot{\emptyset}_{\text {tulangan }}$ & $\mathrm{mm}$ & 19 & 19 & 19 & 19 & 19 & 19 \\
\hline $\mathrm{n}$ tul. tarik & buah & 10 & 10 & 10 & 9 & 9 & 9 \\
\hline n tul. tekan & buah & 3 & 3 & 3 & 3 & 3 & 3 \\
\hline $\mathrm{A}_{\mathrm{s}}$ & $\mathrm{mm}^{2}$ & 2835 & 2835 & 2835 & 2835 & 2835 & 2835 \\
\hline $\mathrm{A}_{\mathrm{s}}{ }^{\prime}$ & $\mathrm{mm}^{2}$ & 851 & 851 & 851 & 851 & 851 & 851 \\
\hline$\rho$ & & 0.0222 & 0.0222 & 0.0222 & 0.0222 & 0.0222 & 0.0222 \\
\hline$\rho^{\prime}$ & & 0.0067 & 0.0067 & 0.0067 & 0.0067 & 0.0067 & 0.0067 \\
\hline$\rho-\rho^{\prime}$ & & 0.0156 & 0.0156 & 0.0156 & 0.0156 & 0.0156 & 0.0156 \\
\hline & & tul tekan & tul tekan & tul tekan & tul tekan & tul tekan & tul tekan \\
\hline$\left(\rho-\rho^{\prime}\right) \geq K$ & & belum & belum & belum & belum & belum & belum \\
\hline & & leleh & leleh & leleh & leleh & leleh & leleh \\
\hline$\rho b$ & & 0.0225 & 0.0225 & 0.0225 & 0.0225 & 0.0225 & 0.0225 \\
\hline$\rho_{\text {maks }}$ & & 0.0169 & 0.0141 & 0.0141 & 0.0169 & 0.0141 & 0.0141 \\
\hline$\left(\rho-\rho^{\prime}\right) \leq$ & & ok & not ok & not ok & ok & not ok & not ok \\
\hline pmaks & & $\begin{array}{l}\text { terkendali } \\
\text { tarik }\end{array}$ & $\begin{array}{l}\text { terkendali } \\
\text { tekan }\end{array}$ & $\begin{array}{l}\text { terkendali } \\
\text { tekan }\end{array}$ & $\begin{array}{l}\text { terkendali } \\
\text { tarik }\end{array}$ & $\begin{array}{l}\text { terkendali } \\
\text { tekan }\end{array}$ & $\begin{array}{l}\text { terkendali } \\
\text { tekan }\end{array}$ \\
\hline$\rho_{\min }$ & & 0.0035 & 0.0035 & 0.0035 & 0.0035 & 0.0035 & 0.0035 \\
\hline $\begin{array}{c}\text { Syarat } \\
\rho_{\text {min }}<\left(\rho-\rho^{\prime}\right)\end{array}$ & & memenuhi & memenuhi & memenuhi & memenuhi & memenuhi & memenuhi \\
\hline
\end{tabular}




\begin{tabular}{|c|c|c|c|c|c|c|c|}
\hline & \multirow{2}{*}{ Satuan } & \multicolumn{3}{|c|}{ Tumpuan } & \multicolumn{3}{|c|}{ Lapangan } \\
\hline & & SNI 2002 & SNI 2013 & SNI 2019 & SNI 2002 & SNI 2013 & SNI 2019 \\
\hline \multicolumn{8}{|l|}{$<\rho_{\text {maks }}$} \\
\hline$\beta_{1}$ & & 0.85 & 0.85 & 0.85 & 0.85 & 0.85 & 0.85 \\
\hline $\mathrm{a}$ & $\mathrm{mm}$ & 149.983 & 149.983 & 149.983 & 149.983 & 149.983 & 149.983 \\
\hline $\mathrm{c}$ & $\mathrm{mm}$ & 176.451 & 176.451 & 176.451 & 176.451 & 176.451 & 176.451 \\
\hline$\varepsilon_{\mathrm{t}}$ & & 0.0042 & 0.0042 & 0.0042 & 0.0042 & 0.0042 & 0.0042 \\
\hline$\varepsilon_{\mathrm{t}}>0.005$ & & transisi & transisi & transisi & transisi & transisi & transisi \\
\hline $\mathrm{M}_{\mathrm{n}}$ & $\mathrm{kNm}$ & 396.91 & 396.91 & 396.91 & 396.91 & 396.91 & 396.91 \\
\hline $\mathrm{M}_{\mathrm{r}}$ & $\mathrm{kNm}$ & 317.53 & 357.22 & 357.22 & 317.53 & 357.22 & 357.22 \\
\hline $\begin{array}{c}\text { Syarat } M_{r}> \\
M_{u}\end{array}$ & & memenuhi & memenuhi & memenuhi & memenuhi & memenuhi & memenuhi \\
\hline
\end{tabular}

Tabel 4 Hasil analisis tulangan lentur balok B3

\begin{tabular}{|c|c|c|c|c|c|c|c|}
\hline & \multirow{2}{*}{ Satuan } & \multicolumn{3}{|c|}{ Tumpuan } & \multicolumn{3}{|c|}{ Lapangan } \\
\hline & & SNI 2002 & SNI 2013 & SNI 2019 & SNI 2002 & SNI 2013 & SNI 2019 \\
\hline$\overline{\mathrm{M}_{\mathrm{u}}}$ & $\mathrm{kNm}$ & 180 & 180 & 180 & 115 & 115 & 115 \\
\hline$\dot{\emptyset}_{\text {tulangan }}$ & $\mathrm{mm}$ & 19 & 19 & 19 & 19 & 19 & 19 \\
\hline $\mathrm{n}$ tul. tarik & buah & 8 & 8 & 8 & 8 & 8 & 8 \\
\hline n tul. tekan & buah & 3 & 3 & 3 & 3 & 3 & 3 \\
\hline $\mathrm{A}_{\mathrm{s}}$ & $\mathrm{mm}^{2}$ & 2268 & 2268 & 2268 & 2268 & 2268 & 2268 \\
\hline $\mathrm{A}_{\mathrm{s}}$ & $\mathrm{mm}^{2}$ & 851 & 851 & 851 & 851 & 851 & 851 \\
\hline$\rho$ & & 0.0279 & 0.0279 & 0.0279 & 0.0279 & 0.0279 & 0.0279 \\
\hline$\rho^{\prime}$ & & 0.0105 & 0.0105 & 0.0105 & 0.0105 & 0.0105 & 0.0105 \\
\hline$\rho-\rho^{\prime}$ & & 0.0174 & 0.0174 & 0.0174 & 0.0174 & 0.0174 & 0.0174 \\
\hline & & tul tekan & tul tekan & tul tekan & tul tekan & tul tekan & tul tekan \\
\hline$\left(\rho-\rho^{\prime}\right) \geq K$ & & belum & belum & belum & belum & belum & belum \\
\hline & & leleh & leleh & leleh & leleh & leleh & leleh \\
\hline$\rho b$ & & 0.0225 & 0.0225 & 0.0225 & 0.0225 & 0.0225 & 0.0225 \\
\hline$\rho_{\text {maks }}$ & & 0.0169 & 0.0141 & 0.0141 & 0.0169 & 0.0141 & 0.0141 \\
\hline$\left(0-a_{1}\right)<$ & & not ok & not ok & not ok & not ok & not ok & not ok \\
\hline $\begin{array}{c}(\rho-\rho) \leq \\
\rho m a k s\end{array}$ & & $\begin{array}{l}\text { terkendali } \\
\text { tekan }\end{array}$ & $\begin{array}{l}\text { terkendali } \\
\text { tekan }\end{array}$ & $\begin{array}{l}\text { terkendali } \\
\text { tekan }\end{array}$ & $\begin{array}{l}\text { terkendali } \\
\text { tekan }\end{array}$ & $\begin{array}{l}\text { terkendali } \\
\text { tekan }\end{array}$ & $\begin{array}{l}\text { terkendali } \\
\text { tekan }\end{array}$ \\
\hline$\rho_{\min }$ & & 0.0035 & 0.0035 & 0.0035 & 0.0035 & 0.0035 & 0.0035 \\
\hline Syarat & & & & & & & \\
\hline$\rho_{\min }<\left(\rho-\rho^{\prime}\right)$ & & memenuhi & memenuhi & memenuhi & memenuhi & memenuhi & memenuhi \\
\hline$<\rho_{\text {maks }}$ & & & & & & & \\
\hline$\beta_{1}$ & & 0.85 & 0.85 & 0.85 & 0.85 & 0.85 & 0.85 \\
\hline $\mathrm{a}$ & $\mathrm{mm}$ & 128.544 & 128.544 & 128.544 & 128.544 & 128.544 & 128.544 \\
\hline $\mathrm{c}$ & $\mathrm{mm}$ & 151.229 & 151.229 & 151.229 & 151.229 & 151.229 & 151.229 \\
\hline$\varepsilon_{\mathrm{t}}$ & & 0.0034 & 0.0034 & 0.0034 & 0.0034 & 0.0034 & 0.0034 \\
\hline$\varepsilon_{\mathrm{t}}>0.005$ & & $\begin{array}{l}\text { bukan } \\
\text { tarik }\end{array}$ & $\begin{array}{l}\text { bukan } \\
\text { tarik }\end{array}$ & $\begin{array}{l}\text { bukan } \\
\text { tarik }\end{array}$ & $\begin{array}{l}\text { bukan } \\
\text { tarik }\end{array}$ & $\begin{array}{l}\text { bukan } \\
\text { tarik }\end{array}$ & $\begin{array}{l}\text { bukan } \\
\text { tarik }\end{array}$ \\
\hline $\mathrm{M}_{\mathrm{n}}$ & $\mathrm{kNm}$ & 232.88 & 232.88 & 232.88 & 232.88 & 232.88 & 232.88 \\
\hline $\mathrm{M}_{\mathrm{r}}$ & $\mathrm{kNm}$ & 186.30 & 209.59 & 209.59 & 186.30 & 209.59 & 209.59 \\
\hline $\begin{array}{c}\text { Syarat } M_{r}> \\
M_{u}\end{array}$ & & memenuhi & memenuhi & memenuhi & memenuhi & memenuhi & memenuhi \\
\hline
\end{tabular}


Tabel 5 Hasil analisis tulangan lentur balok B4

\begin{tabular}{|c|c|c|c|c|c|c|c|}
\hline & \multirow{2}{*}{ Satuan } & \multicolumn{3}{|c|}{ Tumpuan } & \multicolumn{3}{|c|}{ Lapangan } \\
\hline & & SNI 2002 & SNI 2013 & SNI 2019 & SNI 2002 & SNI 2013 & SNI 2019 \\
\hline $\mathrm{M}_{\mathrm{u}}$ & $\mathrm{kNm}$ & 63 & 63 & 63 & 19 & 19 & 19 \\
\hline$\dot{\emptyset}_{\text {tulangan }}$ & $\mathrm{mm}$ & 16 & 16 & 16 & 16 & 16 & 16 \\
\hline $\mathrm{n}$ tul. tarik & buah & 6 & 6 & 6 & 6 & 6 & 6 \\
\hline n tul. tekan & buah & 2 & 2 & 2 & 2 & 2 & 2 \\
\hline $\mathrm{A}_{\mathrm{s}}$ & $\mathrm{mm}^{2}$ & 1206 & 1206 & 1206 & 1206 & 1206 & 1206 \\
\hline$A_{s}{ }^{\prime}$ & $\mathrm{mm}^{2}$ & 402 & 402 & 402 & 402 & 402 & 402 \\
\hline$\rho$ & & 0.0268 & 0.0268 & 0.0268 & 0.0268 & 0.0268 & 0.0268 \\
\hline$\rho^{\prime}$ & & 0.0089 & 0.0089 & 0.0089 & 0.0089 & 0.0089 & 0.0089 \\
\hline$\rho-\rho^{\prime}$ & & 0.0179 & 0.0179 & 0.0179 & 0.0179 & 0.0179 & 0.0179 \\
\hline & & tul tekan & tul tekan & tul tekan & tul tekan & tul tekan & tul tekan \\
\hline$\left(\rho-\rho^{\prime}\right) \geq K$ & & belum & belum & belum & belum & belum & belum \\
\hline & & leleh & leleh & leleh & leleh & leleh & leleh \\
\hline$\rho b$ & & 0.0225 & 0.0225 & 0.0225 & 0.0225 & 0.0225 & 0.0225 \\
\hline$\rho_{\text {maks }}$ & & 0.0169 & 0.0141 & 0.0141 & 0.0169 & 0.0141 & 0.0141 \\
\hline$\left(\rho-\rho^{\prime}\right)<$ & & not ok & not ok & not ok & not ok & not ok & not ok \\
\hline $\begin{array}{l}\text { pmaks } \\
\text { pma }=\end{array}$ & & $\begin{array}{l}\text { terkendali } \\
\text { tekan }\end{array}$ & $\begin{array}{l}\text { terkendali } \\
\text { tekan }\end{array}$ & $\begin{array}{l}\text { terkendali } \\
\text { tekan }\end{array}$ & $\begin{array}{l}\text { terkendali } \\
\text { tekan }\end{array}$ & $\begin{array}{l}\text { terkendali } \\
\text { tekan }\end{array}$ & $\begin{array}{l}\text { terkendali } \\
\text { tekan }\end{array}$ \\
\hline$\rho_{\min }$ & & 0.0035 & 0.0035 & 0.0035 & 0.0035 & 0.0035 & 0.0035 \\
\hline Syarat & & & & & & & \\
\hline $\begin{array}{c}\rho_{\min }<(\rho- \\
\left.\rho^{\prime}\right)\end{array}$ & & memenuhi & memenuhi & memenuhi & memenuhi & memenuhi & memenuhi \\
\hline$<\rho_{\text {maks }}$ & & & & & & & \\
\hline$\beta_{1}$ & & 0.85 & 0.85 & 0.85 & 0.85 & 0.85 & 0.85 \\
\hline a & $\mathrm{mm}$ & 91.169 & 91.169 & 91.169 & 91.169 & 91.169 & 91.169 \\
\hline $\mathrm{c}$ & $\mathrm{mm}$ & 107.258 & 107.258 & 107.258 & 107.258 & 107.258 & 107.258 \\
\hline$\varepsilon_{\mathrm{t}}$ & & 0.0033 & 0.0033 & 0.0033 & 0.0033 & 0.0033 & 0.0033 \\
\hline$\varepsilon_{\mathrm{t}}>0.005$ & & $\begin{array}{l}\text { bukan } \\
\text { tarik }\end{array}$ & $\begin{array}{c}\text { bukan } \\
\text { tarik }\end{array}$ & $\begin{array}{l}\text { bukan } \\
\text { tarik }\end{array}$ & $\begin{array}{c}\text { bukan } \\
\text { tarik }\end{array}$ & $\begin{array}{l}\text { bukan } \\
\text { tarik }\end{array}$ & $\begin{array}{c}\text { bukan } \\
\text { tarik }\end{array}$ \\
\hline $\mathrm{M}_{\mathrm{n}}$ & $\mathrm{kNm}$ & 81.82 & 81.82 & 81.82 & 81.82 & 81.82 & 81.82 \\
\hline $\mathrm{M}_{\mathrm{r}}$ & $\mathrm{kNm}$ & 65.46 & 73.64 & 73.64 & 65.46 & 73.64 & 73.64 \\
\hline $\begin{array}{c}\text { Syarat } M_{r}> \\
M_{u}\end{array}$ & & memenuhi & memenuhi & memenuhi & memenuhi & memenuhi & memenuhi \\
\hline
\end{tabular}

Tabel 6 Hasil analisis tulangan geser balok B1

\begin{tabular}{|c|c|c|c|c|c|c|c|}
\hline & \multirow{2}{*}{ Satuan } & \multicolumn{3}{|c|}{ Tumpuan } & \multicolumn{3}{|c|}{ Lapangan } \\
\hline & & SNI 2002 & SNI 2013 & SNI 2019 & SNI 2002 & SNI 2013 & SNI 2019 \\
\hline $\mathrm{Vu}$ & $\mathrm{kN}$ & 342 & 342 & 342 & 178 & 178 & 178 \\
\hline$\varnothing$ sengkang & $\mathrm{mm}$ & 10 & 10 & 10 & 10 & 10 & 10 \\
\hline $\mathrm{s}$ & $\mathrm{mm}$ & 125 & 125 & 125 & 300 & 300 & 300 \\
\hline Av & $\mathrm{mm} 2$ & 157.00 & 157.00 & 157.00 & 157.00 & 157.00 & 157.00 \\
\hline $\mathrm{Vc}$ & $\mathrm{kN}$ & 185.245 & 188.950 & 188.950 & 185.245 & 188.950 & 188.950 \\
\hline $\begin{array}{c}\text { Kecukupan } \\
\text { penampang } \\
\text { menahan } \\
\text { geser }\end{array}$ & & cukup & cukup & cukup & cukup & cukup & cukup \\
\hline Vs & $\mathrm{kN}$ & 306.46 & 306.46 & 306.46 & 127.69 & 127.69 & 127.69 \\
\hline$\phi \cdot(\mathrm{Vc}+\mathrm{Vs})$ & $\mathrm{kN}$ & 368.78 & 371.561 & 371.561 & 234.70 & 237.483 & 237.483 \\
\hline $\begin{array}{c}\phi \cdot(\mathrm{Vc}+\mathrm{Vs}) \\
>\mathrm{Vu}\end{array}$ & & memenuhi & memenuhi & memenuhi & memenuhi & memenuhi & memenuhi \\
\hline
\end{tabular}


Tabel 7 Hasil analisis tulangan geser balok B2

\begin{tabular}{|c|c|c|c|c|c|c|c|}
\hline & \multirow{2}{*}{ Satuan } & \multicolumn{3}{|c|}{ Tumpuan } & \multicolumn{3}{|c|}{ Lapangan } \\
\hline & & SNI 2002 & SNI 2013 & SNI 2019 & SNI 2002 & SNI 2013 & SNI 2019 \\
\hline $\mathrm{Vu}$ & $\mathrm{kN}$ & 140 & 140 & 140 & 105 & 105 & 105 \\
\hline$\varnothing$ sengkang & $\mathrm{mm}$ & 10 & 10 & 10 & 10 & 10 & 10 \\
\hline $\mathrm{s}$ & $\mathrm{mm}$ & 200 & 200 & 200 & 250 & 250 & 250 \\
\hline Av & $\mathrm{mm} 2$ & 157.00 & 157.00 & 157.00 & 157.00 & 157.00 & 157.00 \\
\hline $\mathrm{Vc}$ & $\mathrm{kN}$ & 96.798 & 98.734 & 98.734 & 96.798 & 98.734 & 98.734 \\
\hline $\begin{array}{c}\text { Kecukupan } \\
\text { penampang } \\
\text { menahan } \\
\text { geser }\end{array}$ & & cukup & cukup & cukup & cukup & cukup & cukup \\
\hline Vs & $\mathrm{kN}$ & 133.45 & 133.45 & 133.45 & 106.76 & 106.76 & 106.76 \\
\hline$\phi .(\mathrm{Vc}+\mathrm{Vs})$ & $\mathrm{kN}$ & 172.69 & 174.138 & 174.138 & 152.67 & 154.121 & 154.121 \\
\hline $\begin{array}{c}\phi \cdot(\mathrm{Vc}+\mathrm{Vs}) \\
>\mathrm{Vu}\end{array}$ & & memenuhi & memenuhi & memenuhi & memenuhi & memenuhi & memenuhi \\
\hline
\end{tabular}

Tabel 8 Hasil analisis tulangan geser balok B3

\begin{tabular}{|c|c|c|c|c|c|c|c|}
\hline & \multirow{2}{*}{ Satuan } & \multicolumn{3}{|c|}{ Tumpuan } & \multicolumn{3}{|c|}{ Lapangan } \\
\hline & & SNI 2002 & SNI 2013 & SNI 2019 & SNI 2002 & SNI 2013 & SNI 2019 \\
\hline $\mathrm{Vu}$ & $\mathrm{kN}$ & 85 & 85 & 85 & 53 & 53 & 53 \\
\hline$\varnothing$ sengkang & $\mathrm{mm}$ & 10 & 10 & 10 & 10 & 10 & 10 \\
\hline $\mathrm{s}$ & $\mathrm{mm}$ & 200 & 200 & 200 & 250 & 250 & 250 \\
\hline Av & $\mathrm{mm} 2$ & 157.00 & 157.00 & 157.00 & 157.00 & 157.00 & 157.00 \\
\hline $\mathrm{Vc}$ & $\mathrm{kN}$ & 61.685 & 62.919 & 62.919 & 61.685 & 62.919 & 62.919 \\
\hline $\begin{array}{c}\text { Kecukupan } \\
\text { penampang } \\
\text { menahan } \\
\text { geser }\end{array}$ & & cukup & cukup & cukup & cukup & cukup & cukup \\
\hline Vs & $\mathrm{kN}$ & 102.05 & 102.05 & 102.05 & 81.64 & 81.64 & 81.64 \\
\hline$\phi \cdot(\mathrm{Vc}+\mathrm{Vs})$ & $\mathrm{kN}$ & 122.80 & 123.727 & 123.727 & 107.49 & 108.419 & 108.419 \\
\hline $\begin{array}{c}\phi \cdot(\mathrm{Vc}+\mathrm{Vs}) \\
>\mathrm{Vu}\end{array}$ & & memenuhi & memenuhi & memenuhi & memenuhi & memenuhi & memenuhi \\
\hline
\end{tabular}

Tabel 9 Hasil analisis tulangan geser balok B4

\begin{tabular}{|c|c|c|c|c|c|c|c|}
\hline & \multirow{2}{*}{ Satuan } & \multicolumn{3}{|c|}{ Tumpuan } & \multicolumn{3}{|c|}{ Lapangan } \\
\hline & & SNI 2002 & SNI 2013 & SNI 2019 & SNI 2002 & SNI 2013 & SNI 2019 \\
\hline$\overline{\mathrm{Vu}}$ & $\overline{\mathrm{kNN}}$ & 26 & 26 & 26 & 16 & 16 & 16 \\
\hline$\varnothing$ sengkang & $\mathrm{mm}$ & 10 & 10 & 10 & 10 & 10 & 10 \\
\hline $\mathrm{s}$ & $\mathrm{mm}$ & 200 & 200 & 200 & 250 & 250 & 250 \\
\hline Av & $\mathrm{mm} 2$ & 157.00 & 157.00 & 157.00 & 157.00 & 157.00 & 157.00 \\
\hline $\mathrm{Vc}$ & $\mathrm{kN}$ & 34.164 & 34.847 & 34.847 & 34.164 & 34.847 & 34.847 \\
\hline $\begin{array}{c}\text { Kecukupan } \\
\text { penampang } \\
\text { menahan } \\
\text { geser }\end{array}$ & & cukup & cukup & cukup & cukup & cukup & cukup \\
\hline Vs & $\mathrm{kN}$ & 70.65 & 70.65 & 70.65 & 56.52 & 56.52 & 56.52 \\
\hline$\phi \cdot(\mathrm{Vc}+\mathrm{Vs})$ & $\mathrm{kN}$ & 78.61 & 79.123 & 79.123 & 68.01 & 68.526 & 68.526 \\
\hline $\begin{array}{c}\phi \cdot(\mathrm{Vc}+\mathrm{Vs}) \\
>\mathrm{Vu}\end{array}$ & & memenuhi & memenuhi & memenuhi & memenuhi & memenuhi & memenuhi \\
\hline
\end{tabular}

